ments contain much about Darwin's views on man, mind, and materialism in relation to evolution, is certainly true. Indeed, the major significance of this book lies in showing that at a very early stage Darwin understood that his idea of evolution by natural selection had vast materialist implications for human evolution and psychology.

Yet Gruber's conclusion that Darwin put off publication of his ideas primarily from fear of persecution and ridicule for his materialist ideas is drawn from shaky evidence. Gruber even resorts to interpreting a dream briefly reported by Darwin, and argues that a photograph of Darwin taken in 1854 reveals "the strain of long years of delay".

A different interpretation is possible. Darwin had high standards for his published work. He later commented that he benefitted from the delay in publishing his works on evolution because he was able to gather better evidence and think through possible objections. Perhaps he was motivated not so much by fear of ridicule as a materialist, as by the feeling that his own standards of argument and evidence had not been attained.

After giving the impression that he admires Darwin's materialism, Gruber's last chapter, "Creative Thought: The Work of Purposeful Beings", contains a surprise. His theory of creativity is vitalistic nonsense. It follows the tradition of Alfred Russel Wallace's mysticism (after 1864) rather than Darwin's materialism. Gruber's theory is that each individual organism functions "according to its own internal laws or organisation". When two organisms interact, the result is behaviour which is utterly unpredictable from a consideration of the special laws governing the individual organisms. A human has, in addition, an internal unpredictable creativity resulting from the interaction of the separate parts of his thought, each of which has a life of its own. So in the end the reader discovers that in his analysis of Darwin's creativity, Gruber is conducting the inquiry under the assumption that the creative process is inherently inscrutable. Darwin spent his life reducing complex biological behaviour to materialist laws. He intensely disliked Wallace's mysticism about human minds, and he would have been appalled to have Gruber's vitalistic theory applied to himself.

Does this book as a whole open up a fruitful field of Darwin research? I hope not. By focusing almost entirely upon Darwin's theory construction of 1837-39, the authors have missed the most important and influential part of Darwin's genius. As he himself believed, Darwin is important not because he outlined the theory of evolution by natural selection in the late $1830 \mathrm{~s}$, but because for the rest of his life he refined and supplemented the theory, found evidence for it, and presented it in enormously influential published works. Michael Ghiselin's The Triumph of the Darwinian Method (The University of California Press: Berkeley and London, 1973) is a step in the right direction, but the vast and important problem of Darwin's influence through his letters and published works in the second half of the nineteenth century has scarcely been touched. The $M$ and $\mathrm{N}$ notebooks seem inconsequential in comparison.

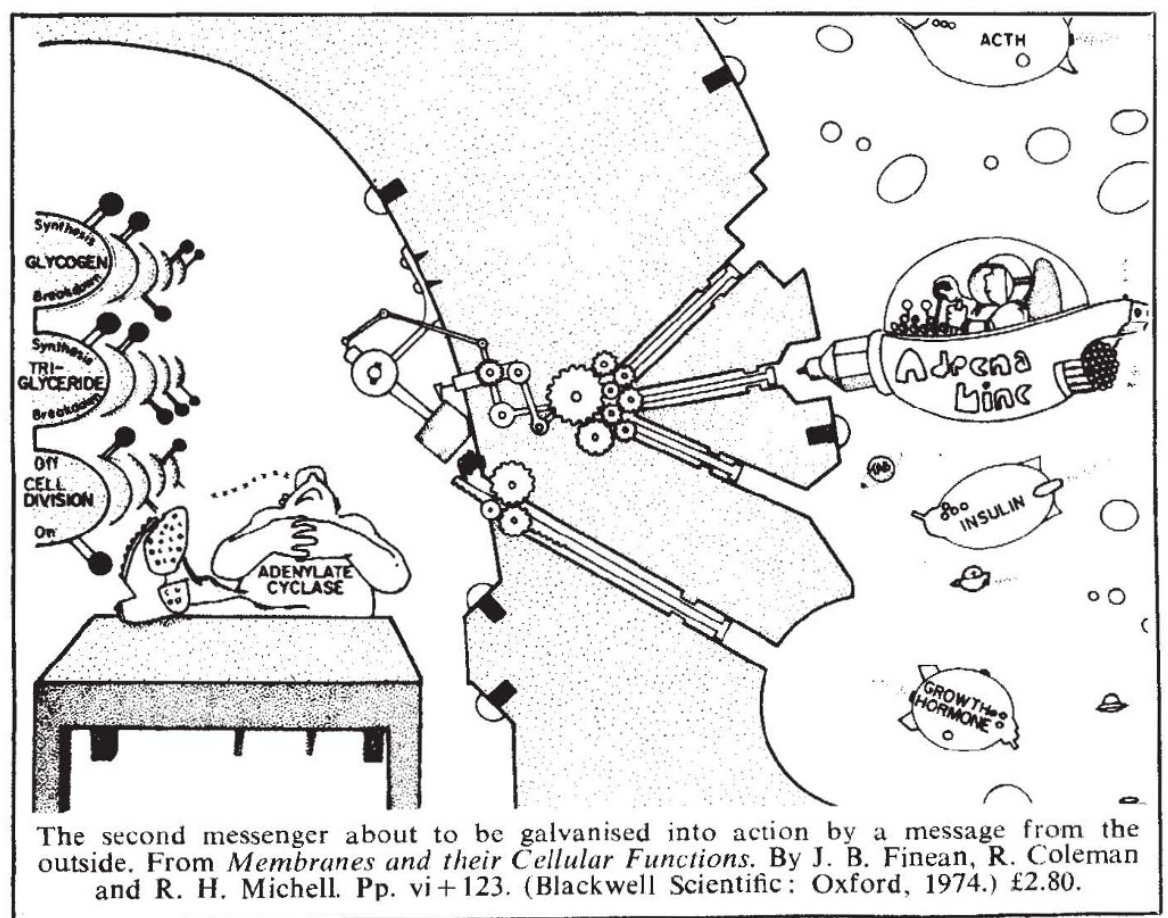

\section{Elementary world climatology}

World Climatology. By John G. Lockwood. Pp. xiv +330. (Arnold: London, March 1974.) $£ 8.50$.

THE study of climatic change and its effect on the environment is one of the most important branches of modern science, in terms of the potential direct effects on the lives of nonscientists. As a result of developments in several fields including studies of the Earth's magnetic field and astronomy, as well as the more conventional aspects of meteorology (which now include use of satellite observations and high speed computers), a synthesis leading to an understanding of at least some aspects of climatic change seems to be in the offing. As a result, many people who have no formal training in meteorology are working in areas where some detailed understanding of the working of the atmosphere is essential. Those people would find this book invaluable.

World Climatology is not concerned with climatic change at all, but with the physical basis of climatology with particular reference to environmentally important aspects. It is intended, says the author "for students taking university courses on climatology, particularly those at an advanced level" and the reader is warned that an acquaintance with basic concepts of meteorology, mathematics and physics is required. But these assumed basics are, in fact, at the most elementary level, and the book introduces gently such concepts as the Stefan-Boltzmann law of black body radiation.

The first part of the book deals with the basics of climatology: radiation laws, convection and turbulence, precipitation and evaporation, and local microclimates (ranging down to that at the surface of a plant leaf). The second and third parts apply these basics to the low latitude atmosphere and to the atmosphere of middle and high latitude regions. With a generous sprinkling of figures-one or more clear and informative line drawings on most pages-and well written text this makes the book ideally suited for its intended readership, but equaly valuable to anyone trying to fill in a knowledge of climatology which is sketchier than it should be.

The publishers of this book have done an excellent job. The clarity of the figures is matched by the clarity of the text. There is a generous bibliography, in the form of references at the end of each chapter.

This book is a good place to find out about the basics of climatology.

John Gribbin 